\title{
Production Efficiency Prediction of Pig Breeding Industry by Optimized LSTM Computer Algorithm under Environmental Regulation
}

\author{
Yunfei Jia, Zhaohui Zhang, Zejun He $\mathbb{D}^{\mathrm{D}}$, Panpan Zhu, Yibei Zhang, and Tianhua Sun \\ Institute of Economics and Management, Henan Agricultural University, Zhengzhou, Henan 450046, China \\ Correspondence should be addressed to Zejun He; ndxbjyf@henau.edu.cn
}

Received 11 October 2021; Revised 28 October 2021; Accepted 3 November 2021; Published 26 December 2021

Academic Editor: Le Sun

Copyright (c) 2021 Yunfei Jia et al. This is an open access article distributed under the Creative Commons Attribution License, which permits unrestricted use, distribution, and reproduction in any medium, provided the original work is properly cited.

\begin{abstract}
The study aims to improve the economic income of pig breeding industry under environmental regulation and control the environmental pollution caused by pig breeding. Long short-term memory (LSTM) neural network combined with environmental regulation is proposed to forecast the price of live pigs, to reduce the cost of environmental pollution control and improve the production efficiency of pig breeding. Primarily, analyses are made on the industrial structure and pollution of pigs in China, and studies are carried out on the inevitability of large-scale and intensive pig breeding. Then, pig breeding and environmental pollution are coordinated under the environmental regulation. From the perspective of green total factor productivity, calculation is made on the profit of pig breeding and the cost of environmental pollution control. Next, the LSTM neural network is used to predict the price of live pigs, thus effectively controlling the scale of pig breeding and making timely decisions that conform to market rules. The results show that with the increase of feed and land prices, the advantages of large-scale pig breeding gradually become prominent, which leads to the small- and medium-sized scale farmers withdrawing from the market. Compared with other similar models, the designed model can better simulate the future trend of hog price, of which the prediction accuracy is over $80 \%$. When combined with environmental regulations, the prediction accuracy of the model for different data sets reaches $83 \%$, so the designed model can better predict the changing trend of the price of live pigs, thus improving the production efficiency of large-scale pig farmers.
\end{abstract}

\section{Introduction}

Pig breeding industry is an important part of China's rural economic system. With the rapid increase of people's demand for pork in recent years, pig breeding industry has developed rapidly [1]. China is the largest country in pork consumption in the world. From 2010 to 2018, Chinese consumed more than 50 million tons of pork every year. Therefore, pork is the main source of meat for Chinese and plays an important role in dietary structure of Chinese, which shows that there is a huge market demand for pork in the domestic market. However, since 2019, under the combined influence of environmental protection policies, large-scale breeding trend, and "swine fever," the slaughter rate of Chinese pigs has decreased, resulting in a severe decline in pork production. However, the intensive and large-scale pig breeding model also poses a challenge to the carrying capacity of the natural environment, which becomes an important agricultural pollution source. Therefore, in the process of agricultural economic development, the government began to pay attention to the sustainable development of pig breeding industry and formulated relevant environmental regulation policy system to centrally control the environmental pollution caused by large-scale pig breeding in rural areas. Under environmental regulation, pig breeding industry requires optimizing regional layout, changing production mode, and promoting green sustainable development [2].

Nevertheless, the increasingly perfect breeding environment regulation policy system cannot effectively curb the environmental pollution of pig industry. With the increasingly serious problems of resources and environment, 
the traditional extensive, high-pollution, and high-yield economic development model cannot meet the standards of social development. Green total factor productivity is an important indicator to measure production efficiency. From the aspect of the growth, the indicator includes green technology progress and green technology efficiency [3]. Green total factor productivity is put forward based on traditional total factor productivity, which refers to the ratio of total output to total production factor input in a system. The improvement of green technology progress and green technology efficiency will lead to the continuous improvement of green total factor participation rate. The harm to the environment in the process of development should be avoided to ensure the sustainable development of the pig breeding industry. By analyzing the influencing factors in green total factor productivity growth of pig breeding under environmental regulation and analyzing the main influencing factors, construction of a perfect environmental protection policy system of pig breeding industry is finished; it improves green total factor productivity and promotes the sustainable development of pig breeding industry [4].

In view of the development of pig breeding industry under environmental regulation, global experts and scholars have done a lot of research. Biddle (2021) studied the regular analysis of statistical samples to predict the supply of various agricultural products and compared it with the actual situation, which proved the effectiveness of regular forecasting in solving practical problems [5]. Xie et al. (2021) studied the application of artificial intelligence technology in the medical field, compared it with the prediction of diseases and drug reactions through deep learning technology, established a framework based on deep learning, and analyzed the prediction methods corresponding to different diseases [6]. The current related research suggests that the development of pig breeding industry under the agricultural environmental regulation has become an important economic variable and academic research hotspot under the new development concept. There are many research works on green total factor productivity of pig industry breeding, combined with the research of China's macroeconomic development and environmental regulation measurement [7]. However, there is a lack of those on the relationship between environmental regulation and green total factor productivity of pig breeding. Therefore, analyses are made on the production efficiency of pig industry under environmental regulation by combining factors such as pig breeding scale, pig price, and environmental control cost. The changing trend of pig price is predicted through neural network model. Studies are released on the relationship between green total factor productivity of pigs and environmental regulation by using panel data combined with environmental control cost, aimed at looking for the inflection point of the optimal agricultural environmental regulation intensity under different pig breeding scales. From these results, the most suitable pig breeding scale can be obtained to realize the green and sustainable development of pig breeding industry and further improve farmers' income.

\section{Environmental Regulation and Production Efficiency of Pig Breeding Industry}

2.1. Industrial Structure of Pig Scale Breeding and Environmental Pollution under Environmental Regulation. With the accelerated consumption of resources and the deteriorating social environment, resource and environmental problems have become an important factor affecting residents' life and social development in China. Therefore, more and more scholars have introduced natural resources and environmental factors into the process of economic growth and put forward the green economic growth theory [8]. Combined with the sustainable development theory, the green economic growth theory is put forward. The theory believes that green economic growth is an economic development model which ensures that natural resources can continue to provide various resources and environmental services for people's happiness, reduces environmental risks and scarcity of ecological resources, and then promotes positive economic growth and development [9]. For a long time, China's pig breeding industry has been dominated by the scattered breeding, with a low degree of scale breeding. However, in recent years, affected by the increase of opportunity cost and environmental protection supervision, retail investors began to withdraw from the pig breeding industry, and the scale of domestic pig breeding is further improving [10]. Moreover, in order to regulate China's pork production, many policy documents have been issued to promote the development of pig industry; promote the pig breeding industry from the perspectives of land, subsidies, and environmental protection; stabilize the supply of pork production, further promote the transformation, upgrading, and development of pig industry; and promote the optimized development of pig breeding industry to a strategic development position [11]. Figure 1 indicates the structure of pig breeding industry chain.

The essence of green economic growth theory is to realize the coordinated development of resources, environment, and economy with the least resource consumption and the least environmental cost. Therefore, the application of green economic growth to pig breeding industry emphasizes adjusting the speed of pig breeding economic growth and ensuring the quality of economic growth, to realize the coordinated development between economy, resources, and environment of pig breeding industry and maximize the comprehensive social welfare. The Market Failure Model holds that some obstacles in the real market make it difficult to allocate resources only by the price mechanism to achieve the Pareto Optimum, and there is a certain loss of efficiency [12]. Therefore, the method of resource allocation in the market is completely generated by the structure of market competition, and also under the influence of external obstacles such as monopoly, information asymmetry, and public goods, the price mechanism will be limited. Merely through the market resource allocation, the resource allocation efficiency cannot achieve the Pareto Optimum, which is manifested as the failure of market mechanism. 


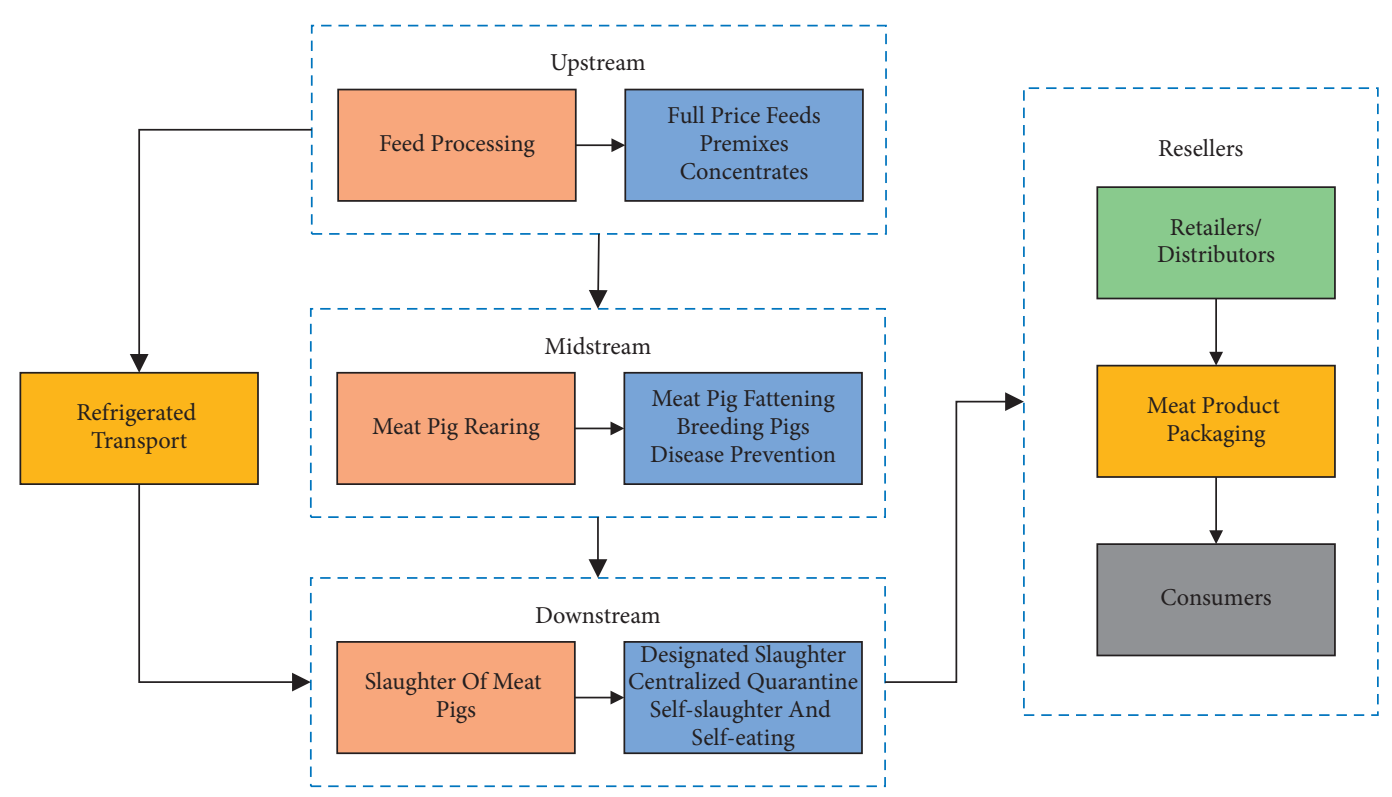

Figure 1: Pig breeding industry chain.

Environmental pollution is the most important embodiment of economic externality. When the business entity produces pollution discharge to the environment in the process of production and business activities, but it does not compensate timely for environmental pollution, it will produce environmentally external economy. From the perspective of private interests, to maximize profits, it is necessary for the business entities to minimize the production cost while ensuring their established income. Therefore, there will be business entities that will transfer the cost of environmental pollution to the society, so that the society will jointly bear the cost of environmental pollution control brought by the entities. Environmental regulation is the environmental binding of the regulation subject to the regulation object. Environmental regulation is generally accepted as the direct intervention of the government in the organization or individual environment that operates business, through the formulation of prohibitions and environmental standards. The main feature is that the government implements environmental norms by forcible means to achieve the protection of the environment. In the research process, by comparing the cost-benefit, environmental pollution and green total factor productivity of the pig breeding industry at different times, regions, and production scales, there can be more understanding of the actual situation of pig breeding to provide a practical basis for the subsequent optimization of production mode, reducing environmental pollution and promoting the transformation of pig breeding industry. The impact of environmental regulation on the green total factor productivity of pig breeding industry is analyzed [13].

After a long period of development, China's pig breeding industry has become an intensive means of production input industry that relies on factors such as capital and labor. Although the overall economic aggregate of the pig breeding industry is increasing, the profits of the industry are generally low and are constrained by resources, environment, and environmental regulations, so the pig breeding industry needs dynamic and green transformation from the original extensive economic growth model to the intensive economic growth model. A new green economic growth industry should be guided by green total factor productivity [14]. As a coordination mechanism combining environment, resources, and economic development, environmental regulation plays an important guiding role in the direction of green economy development. The environmental regulation can inhibit the pollution of pig breeding industry to a certain extent, but it will also affect the economic growth efficiency of pig breeding industry as well [15].

\subsection{Calculation of Pig Breeding Profit and Environmental} Pollution Control Cost. However, from the perspective of the overall development model, environmental regulation can realize the green economic growth of pig breeding industry, promote the emission reduction of pig breeding industry, and improve the efficiency of pig breeding industry. By analogy with the impact of industrial environmental regulation on industrial pollution emission, industrial environmental regulation can not only reduce industrial pollution emission, but also promote the efficiency of economic growth [16]. Compared with the pollution caused by industrial production, due to the small-scale and periodic operation, the environmental pollution produced by the pig breeding industry presents the problems of dispersion, concealment, and difficult monitoring, which increases the difficulty of controlling the environmental pollution of the pig breeding industry [17]. In the macroeconomic system, the total output includes expected output such as economic output value and unexpected output such as environmental pollution cost. When constructing the theoretical model of productivity, it is necessary to consider the traditional means of production such as capital, labor, and land, in addition to the resource and environmental factors, especially the 
environmental pollution factors [18]. By referring to the definition of green total factor productivity, the green total factor productivity of pig breeding is defined, which represents the expected output, such as economic output value in the process of pig breeding, and the proportion of undesired output such as environmental pollution in the input of production factors such as capital, labor, and land. Further, what can be obtained is the ratio between increase of the expected output such as economic output value and the decrease of unexpected outputs such as environmental pollution, in a specific direction under the given input [19].

Compared with the traditional calculation of total factor productivity, resource and environmental factors are focused by green total factor productivity based on input and output, so it is necessary to introduce environmental pollution evaluation indexes such as chemical oxygen demand (COD), total nitrogen (TN), and total phosphorus (TP).
Nonparametric estimation methods, such as data inclusion analysis (DEA), are often used to calculate green total factor productivity. The advantage of the single method lies in its handy calculation and unnecessity of environmental pollution values to be considered. In addition, it does not depend on the specific form of the production function and does not need an assumed specific form of the production function beforehand, so it can be applied to measurement directly by using the linear programming method [20]. Combined with previous studies, the Fixed-WindowMalmquist-Luenberger (FWML) index is used to measure the green total factor productivity (GTFPCH) of pig breeding industry. Green total factor productivity is divided into two parts: green technology efficiency (GEFFCH) and green technology progress (GTECHCH). Equations (1) and (2) provide the specific calculation.

$$
\begin{aligned}
\operatorname{GTFPCH}_{w}^{\text {fixed }} & =\frac{1+\vec{D}_{w}^{\text {fixed }}\left(x^{t}, y^{t}, b\right)}{1+\vec{D}_{w}^{\text {fixed }}\left(x^{t+1}, y^{t+1}, b^{t+1}\right)} \\
\operatorname{GEFFCH}_{w}^{\text {fixed }} & =\frac{1+\vec{D}_{w}^{t}\left(x^{t}, y^{t}, b^{t}\right)}{1+\vec{D}_{w}^{t+1}\left(x^{t+1}, y^{t+1}, b^{t+1}\right)} \\
\mathrm{GTECHCH}_{w}^{\text {fixed }} & =\frac{1+\vec{D}_{w}^{\text {fixed }}\left(x^{t}, y^{t}, b^{t}\right)}{1+\vec{D}_{w}^{t}\left(x^{t}, y^{t}, b^{t}\right)} \times \frac{1+\vec{D}_{w}^{t+1}\left(x^{t+1}, y^{t+1}, b^{t+1}\right)}{1+\vec{D}_{w}^{\text {fixed }}\left(x^{t+1}, y^{t+1}, b^{t+1}\right)}
\end{aligned}
$$

In (1) and (2), $\vec{D}_{w}^{t+1}$ stands for the production reference set based on directional distance function in $t+1$ period under a fixed window, $\vec{D}_{w}^{t}$ refers to the production reference set based on directional distance function in $t$ period under a fixed window, $x$ means input elements, $y$ represents the expected output element, and $b$ is set to be the unexpected output element. The non-angle SBM function is selected as the directional distance function [21].

With panel data, the impact of environmental regulation on the total factors of green productivity, green technology efficiency, and green technology progress of pig breeding is investigated. The panel bidirectional fixed effect model and tool variable method are used to understand the influence and mechanism of green total factor productivity under environmental regulation. The Moran index and the spatial effect brought by spatial Doberman model are used [22, 23]. Combined with the influencing factors of environmental regulation on pig breeding, (4) shows the established empirical model (in (4), $i$ stands for provinces, $t$ refers to time, GTFPCH is the abbreviation of the green total factor productivity of pig breeding, GEFFCH represents the green technical efficiency of pig breeding, GTECHCH means the green technology progress of the pig breeding industry, ERI stands for the environmental regulation intensity, NATRES is the resource endowment status, ECODEV is the economic development level, INDFOU refers to industrial basic status, $M A R E C O$ stands for the market economy condition, TRAINF stands for the transportation infrastructure, $\mu_{\text {area }}$ stands for the regional effect, $\mu_{\text {year }}$ denotes the time effect, and $\varepsilon$ stands for the random disturbance term [24]):

$$
\begin{aligned}
\operatorname{GTFPCH}_{i, t}= & \alpha_{0}+\alpha_{1} \mathrm{ERI}_{i, t}+\beta_{1} \sum \mathrm{NATRES}_{i, t}+\beta_{2} \sum \mathrm{ECODEV}_{i, t} \\
& +\beta_{3} \sum \mathrm{INDFOU}_{i, t}+\beta_{4} \sum \mathrm{MARECO}_{i, t}+\beta_{5} \sum \mathrm{TRAINF}_{i, t}+\mu_{\text {area }}+\mu_{\text {year }}+\varepsilon_{i, t} .
\end{aligned}
$$

To help better understand the influence mechanism of green total factor productivity of pig breeding under environmental regulation, the green total factor productivity is decomposed into green technical efficiency and green technical progress as shown in the following equations: 


$$
\begin{aligned}
\operatorname{GEFFCH}_{i, t}= & \alpha_{0}+\alpha_{1} \mathrm{ERI}_{i, t}+\beta_{1} \sum \mathrm{NATRES}_{i, t}+\beta_{2} \sum \mathrm{ECODEV}_{i, t} \\
& +\beta_{3} \sum \mathrm{INDFOU}_{i, t}+\beta_{4} \sum \mathrm{MARECO}_{i, t}+\beta_{5} \sum \mathrm{TRAINF}_{i, t}+\mu_{\text {area }}+\mu_{\text {year }}+\varepsilon_{i, t}, \\
\mathrm{GTECHCH}_{i, t}= & \alpha_{0}+\alpha_{1} \mathrm{ERI}_{i, t}+\beta_{1} \sum \mathrm{NATRES}_{i, t}+\beta_{2} \sum \mathrm{ECODEV}_{i, t} \\
& +\beta_{3} \sum \mathrm{INDFOU}_{i, t}+\beta_{4} \sum \mathrm{MARECO}_{i, t}+\beta_{5} \sum \mathrm{TRAINF}_{i, t}+\mu_{\text {area }}+\mu_{\text {year }}+\varepsilon_{i, t} .
\end{aligned}
$$

2.3. Relationship between Pig Price and Breeding Scale. The fluctuation of pig price is due to many reasons, which has an impact on pig production and consumption. In China, the pork price is mainly regulated by a dual-track system, which combines the guidance price with the marketregulated price. With the steady improvement of social and economic level, people's income level is constantly improving. People's consumption level and quality of life are constantly improving, which leads to a further increase in the demand for pork, which makes the price of pork constantly increasing. However, with the increasing supply of beef, mutton, fish, and poultry and the increasing pork demand, the price of pork exceeds the per capita consumption level of people; the pork supply is excessive [25]. Figure 2 shows the periodic fluctuation law of pork price.

The majority of small- and medium-sized retail investors in the early pig breeding industry easily lose money in the pig market when the pig price is high and the column is low, resulting in the production capacity of pigs being consistent with the change trend of pig prices. The long-term average price of pork pigs depends on the price of live hogs and is affected by the relationship between market supply and demand in the short term. When breeders expect the price of pork to rise, they will increase the number of sows and stocks, resulting in oversupply in the market; when they expect pork prices to fall, they will reduce the number of sows and stocks, resulting in the market supply of pork short of the demand. The pork price will also be alternated in the fluctuation caused by the two methods, resulting in the continuous fluctuation of pork price. Moreover, China is further banning the retail pig breeding, to ensure the steady prices of pork. However, the intensive and large-scale pig breeding also leads to the gradual formation of a monopoly trend among slaughtering enterprises and intervenes in the purchase price of pigs and the wholesale price of pork. Table 1 shows the classification criteria of pig breeding scale.

The most intuitive economic benefits brought by pig breeding are reflected in the pork price. The fluctuation of the price of pig is as regular as other commodities. The periodic price fluctuation is mainly affected by the relationship between market supply and demand, and the two factors also affect each other. Since 2006, the fluctuation cycle of China's pig price is generally $3 \sim 4$ years, and the pork price shows a trend where it is low in the middle of the curve and high in the two ends of the curve in one year. Specifically, the pork price is high from January to February in every year. It decreases from March and reaches the lowest point from May to July. Then, it begins to recover slowly and reach the peak of a new round before the Spring Festival. However, with the development of social economy, some changes have taken place in the price law of pig market. Judging by the fluctuation of pig price, the overall supply trend of the market, the reluctance of farmers to sell, the scale of pig breeding, and the pig transportation have impacted and restricted the import and terminal demand of pigs [26]. Figure 3 illustrates the influencing factors in pig prices.

\subsection{Prediction Model of Pig Price and Yield Based on LSTM.} Artificial neural network simulates the ability of human brain to process information from the perspective of information processing. Thus, what is established is a network model composed of different connection modes. The neural network contains many neuron nodes, which are interconnected to form an operation model, and each neuron node represents a specific output function. The connection between two nodes represents the weight of the connection signal [27]. The internal connection mode of neural network determines the output result of the network, which can be divided into forward network and feedback network according to the characteristics of network topology. Figure 4(a) shows the structure of the forward neural network, and Figure 4(b) reveals the structure of the feedback neural network. Artificial neural network is characterized by strong self-learning ability, associative storage ability, and ability to find the optimal solution.

The recurrent neural network (RNN) includes input units, output units, and hidden units. After data being put into the neural network and processed, the data of hidden layer and output layer are obtained. The hidden layer plays an important role in RNN. Figure 5(a) indicates the structure of RNN, and Figure 5(b) illustrates the network expansion. Every neuron structure will be used over and over again [28]. Parameter $x_{t}$ represents the input at time $t, o_{t}$ refers to the output at time $t$, and $s_{t}$ means the memory at time $t$. Parameter $s_{t}$ can be calculated according to the output of the input layer and the state of the hidden layer as shown in the following equation:

$$
s_{\mathrm{I}}=f\left(U-x_{\mathrm{T}}+W-s_{r-1}\right) .
$$

Parameter $f$ represents a nonlinear activation function. When calculating the hidden layer state of the word $s_{0}, s-1$ does not exist in fact, which needs to be used. The result is impossible to predict directly with single matrix, so it is necessary to introduce a weight matrix $V$. When prediction begins, $o_{t}$ stands for the output at time $t$, and the equation is

$$
o_{r}=\operatorname{softmax}\left(V \cdot s_{r}\right) .
$$




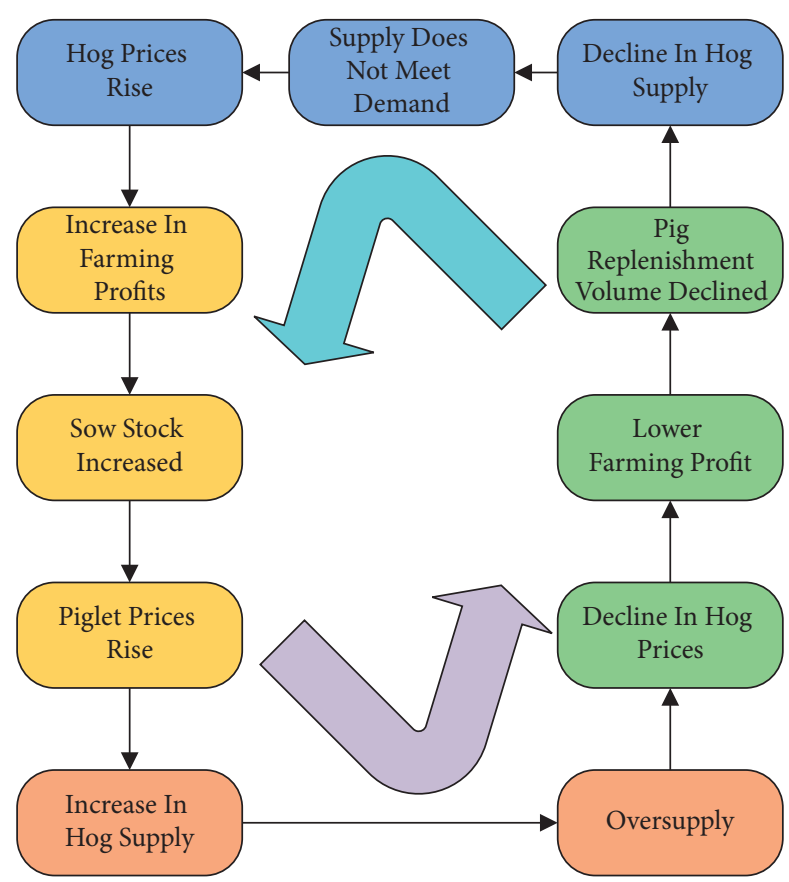

Figure 2: Periodic fluctuation law of pork price.

TABLe 1: Classification standard of pig breeding scale.

\begin{tabular}{|c|c|c|c|}
\hline & Farrow-to-finish & Piglet feeding & Breeding piglets \\
\hline Retail investors & $\begin{array}{c}\text { Scale base: sows }<10, \text { commercial pigs } \\
<160 / \text { year }\end{array}$ & $\begin{array}{c}\text { Scale base: sows }=0 \text {, commercial pigs } \\
<160 / \text { year }\end{array}$ & $\begin{array}{c}\text { Scale based sows }<10 \text {, piglets } \\
<160 / \text { year }\end{array}$ \\
\hline $\begin{array}{l}\text { Small-scale } \\
\text { industries }\end{array}$ & $\begin{array}{c}\text { Scale base: sows }<100, \text { commercial pigs } \\
<1600 / \text { year }\end{array}$ & $\begin{array}{c}\text { Scale base: sows }=0 \text {, commercial pigs } \\
<1600 / \text { year }\end{array}$ & $\begin{array}{c}\text { Scale base: sows }<100 \text {, piglets } \\
<1600 / \text { year }\end{array}$ \\
\hline $\begin{array}{l}\text { Medium-scale } \\
\text { industries }\end{array}$ & $\begin{array}{c}\text { Scale base: sows }<1000, \text { commercial pigs } \\
<10000 / \text { year }\end{array}$ & $\begin{array}{c}\text { Scale base: sows }=0 \text {, commercial pigs } \\
<10000 / \text { year }\end{array}$ & $\begin{array}{c}\text { Scale base: sows }<1000, \text { piglets } \\
<10000 / \text { year }\end{array}$ \\
\hline $\begin{array}{l}\text { Large-scale } \\
\text { industries }\end{array}$ & $\begin{array}{l}\text { Scale base: sows }>3000 \text {, commercial pigs } \\
\qquad>50000 / \text { year }\end{array}$ & $\begin{array}{c}\text { Scale base: sows }=0, \text { commercial pigs } \\
>50000 / \text { year }\end{array}$ & $\begin{array}{c}\text { Scale base: sows }<3000, \text { piglets } \\
<50000 / \text { year }\end{array}$ \\
\hline
\end{tabular}

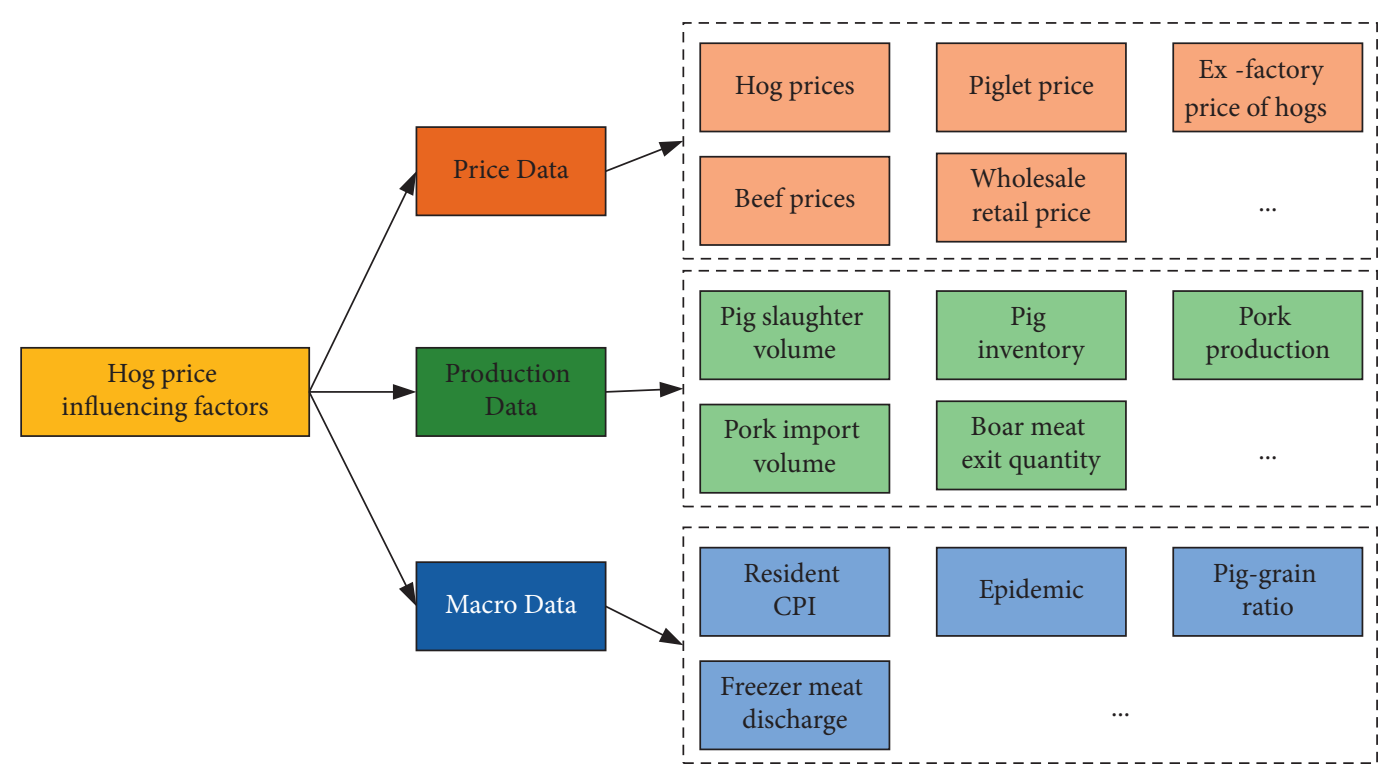

Figure 3: Table of influencing factors in pig price. 


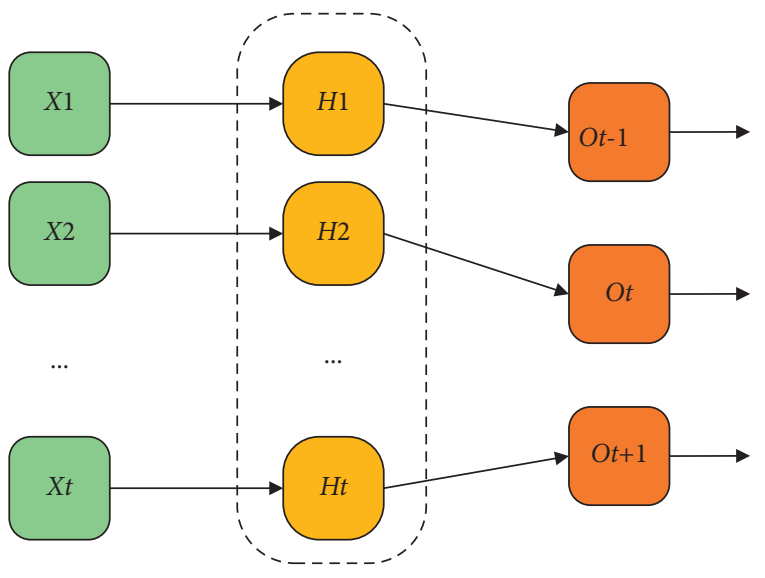

(a)

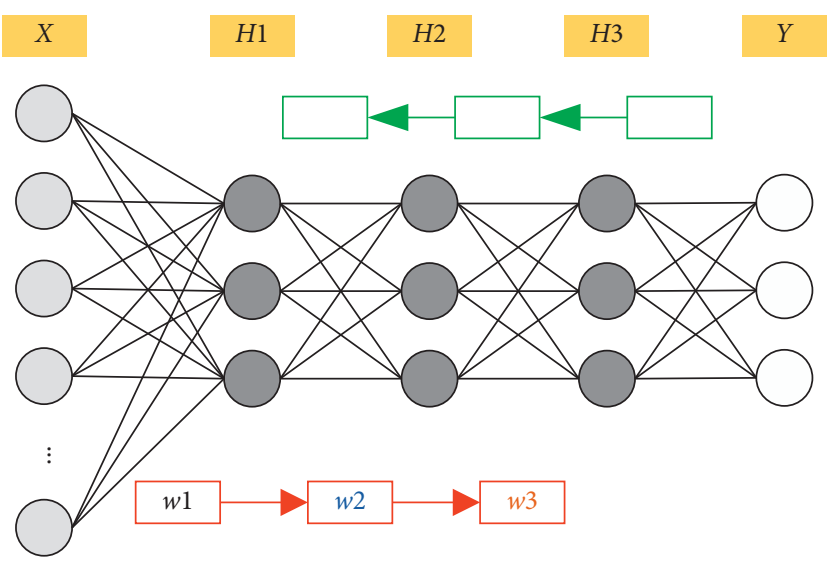

(b)

Figure 4: Structure of feedforward neural network (a) and feedback neural network (b).

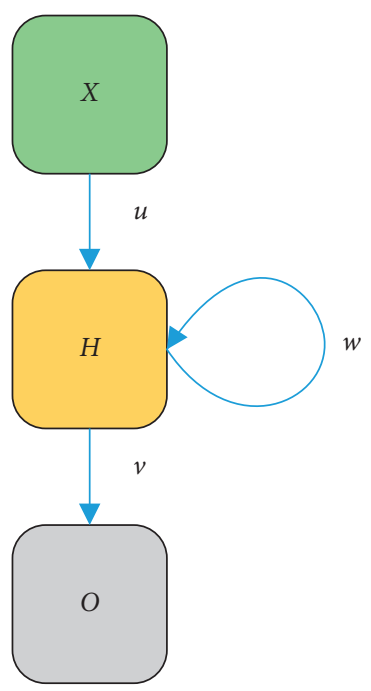

(a)

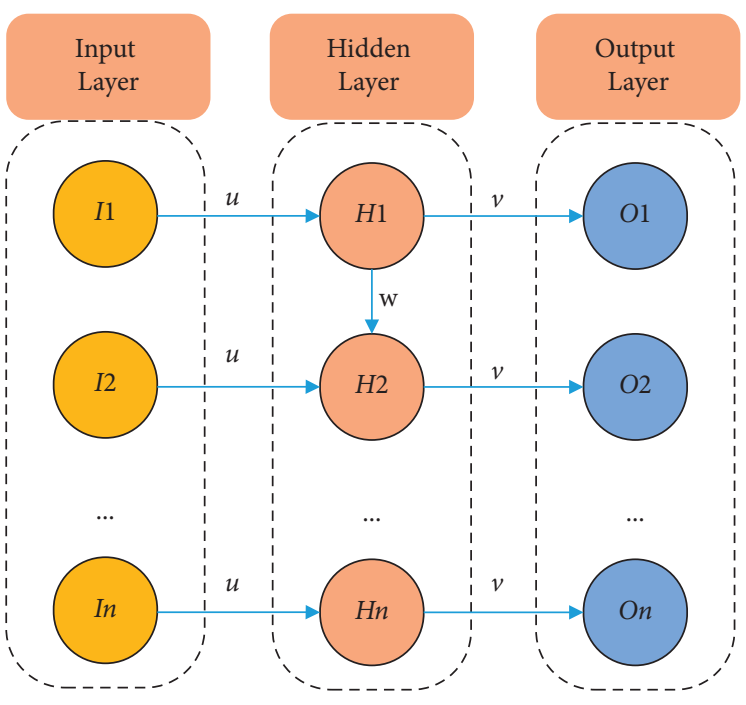

(b)

FIgURE 5: Structure of cyclic neural network: (a) RNN structure; (b) RNN deployment structure.

Figure 5 shows that each memory unit in the network shares a set of parameters $(u, v, w)$, which greatly reduces the amount of calculation of the neural network. However, the neurons are independent of each other; ideal results cannot be obtained when dealing with timing problems. Furthermore, in the process of network training, there is also the problem of gradient disappearance or explosion, which cannot solve the problem of long-term dependence. However, the long short-term memory (LSTM) network solves these problems well. Compared with the cyclic neural network, it has the function of long-term memory [29]. Therefore, it is suitable for processing and predicting the events with relatively long interval and delay in time series. Figure 6 shows the deformed structure of LSTM network. Based on the structure of ordinary cyclic neural network, it adds memory units to each neural unit of hidden layer, to make the memory information on time series controllable. Each time data is transmitted between each unit of hidden layer, it passes through several controllable gates (forgetting gate, input gate, candidate gate, output gate), which can control the memory degree of previous information and current information.

The memory block in the LSTM network structure includes three parts: forgetting gate, input gate and output gate, and a memory unit. The first step of the LSTM neural network is to decide, through the forgetting gate and the sigmoid function, and to control which information can pass through the memory unit [30]. According to the output $h_{t-1}$ at the previous moment and the current input $x_{t}$, a value of $f_{t}$ from 0 to 1 is generated to decide whether to let the information $C_{t-1}$ learned at the previous moment pass or partially pass:

$$
f_{t}=\sigma\left(W_{f}\left[h_{t-1}, x_{t}\right]+b_{f}\right) .
$$

The second step is to generate the updated information, including two values generated by the input layer and the 


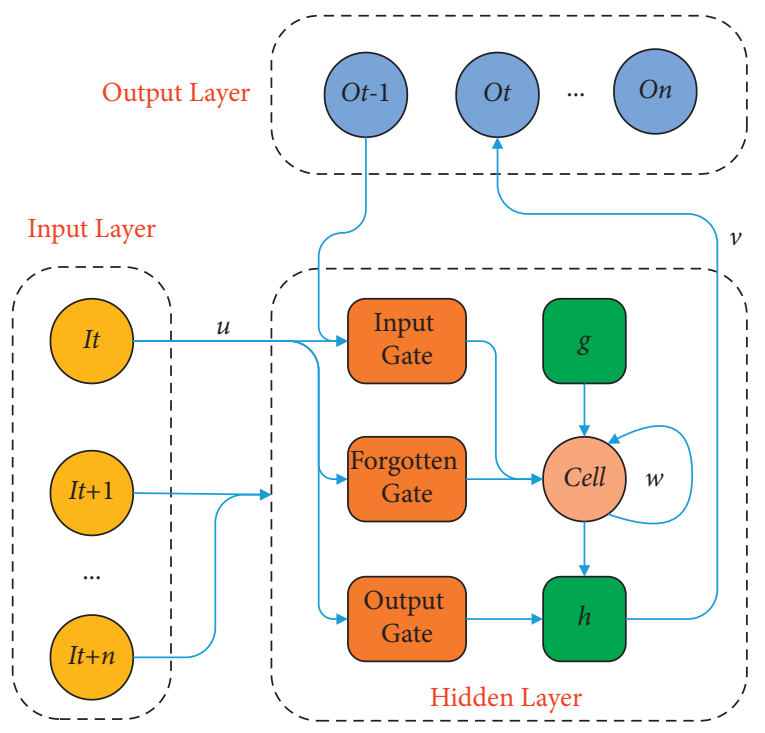

(a)

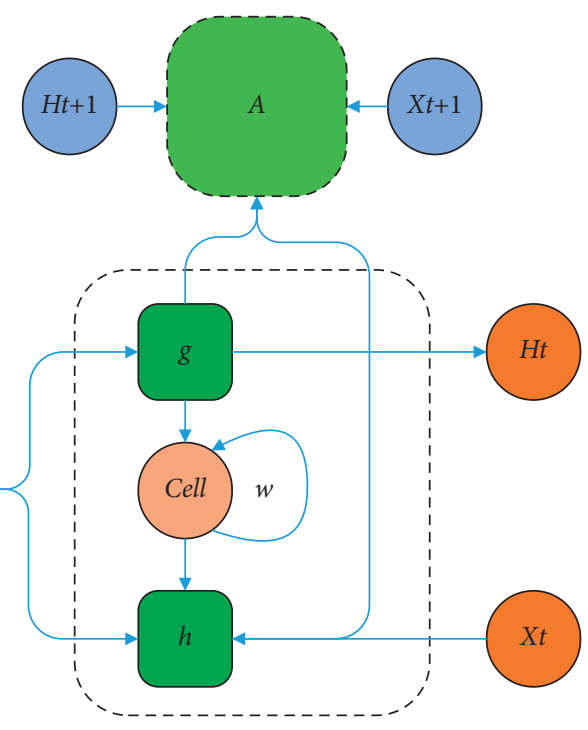

(b)

FIGURE 6: LSTM memory network: (a) LSTM neural network; (b) expansion of LSTM neural network.

tanh, which will be used as candidate values of the hidden layer and added to the memory unit. The equation is

$$
\begin{aligned}
i_{t} & =\sigma\left(W_{i}\left[h_{t-1}, x_{t}\right]+b_{i}\right), \\
\widetilde{C}_{t} & =\tanh \left(W_{c}\left[h_{t-1}, x_{t}\right]+b_{c}\right) .
\end{aligned}
$$

After the information generated by the previous memory unit is multiplied with $f_{t}, i_{t}$ is added to multiply the candidate value to generate a new candidate value. The combination of the two can make the unnecessary information forgotten. Equation (12) illustrates the process of adding new information:

$$
C_{t}=f_{t} \cdot C_{t-1}+i_{t} \cdot \widetilde{C}_{t} .
$$

The last step is to determine the output of the model. An initial output is obtained through the sigmoid layer, and then the value of $\mathrm{Ct}$ is scaled to $[-1,1]$ by using tanh and then multiplied by the output obtained by sigmoid one by one. Thus, the final output of the model is obtained as shown in the following equations:

$$
\begin{aligned}
& o_{t}=\sigma\left(W_{o}\left[h_{t-1}, x_{t}\right]+b_{o}\right), \\
& h_{t}=o_{t} \cdot \tanh \left(C_{t}\right) .
\end{aligned}
$$

2.5. Experimental Methods and Data Sets. The data are selected from the panel data of pig breeding industry in cities of 6 provinces: Heilongjiang, Hebei, Shaanxi, Hunan, Zhejiang, and Guangdong, from 2005 to 2019. Under the consideration of the changes of pig price caused by the differences of provinces in different regions, the model of different provinces is trained to predict the prices of "Shunfeng Pork." In the research process, due to the lack of research data in some provinces, the Difference Method is used to supplement the missing data on the basis of the established research, to improve the research efficiency and comparability of data. The web crawler is used to obtain the transaction price of the Chinese pig market, the quotation of employees, and the pig price of the trading website and save them as an Excel file. To ensure the accuracy of the obtained data, the pig prices of the Statistical Yearbook published by the National Bureau of Statistics is used as the standard price of pigs. In the study, the data of pigs from 2005 to 2015 are selected as the training set and the data from 2016 to 2019 are selected as the test set. The input and parameter selection of the model have a great impact on the results obtained by the model. Therefore, the pig prices of the collected data from the above sources are used as the input of the model, to obtain the real relationship between the collected data and pork price. Figure 7 illustrates the calculation process.

In the process of evaluating the models, the following evaluation criteria are adopted, including four evaluation indexes: Mean Absolute Error (MAE), Mean Absolute Percent Error (MAPE), Mean Square Error (MSE), Root Mean Square Error (RMSE), and Trend Accuracy (TAR).

(1) MAE:

$$
\mathrm{MAE}=\frac{1}{N} \sum_{t=1}^{N}\left|\hat{y}_{t}-y_{t}\right| .
$$

(2) MAPE:

$$
\text { MAPE }=\frac{1}{N} \sum_{t=1}^{N}\left|\frac{\hat{y}_{t}-y_{t}}{y_{t}} \times 100 \%\right| .
$$

(3) MSE:

$$
\text { MSE }=\frac{1}{N} \sum_{t=1}^{N}\left(\hat{y}_{t}-y_{t}\right)^{2} .
$$




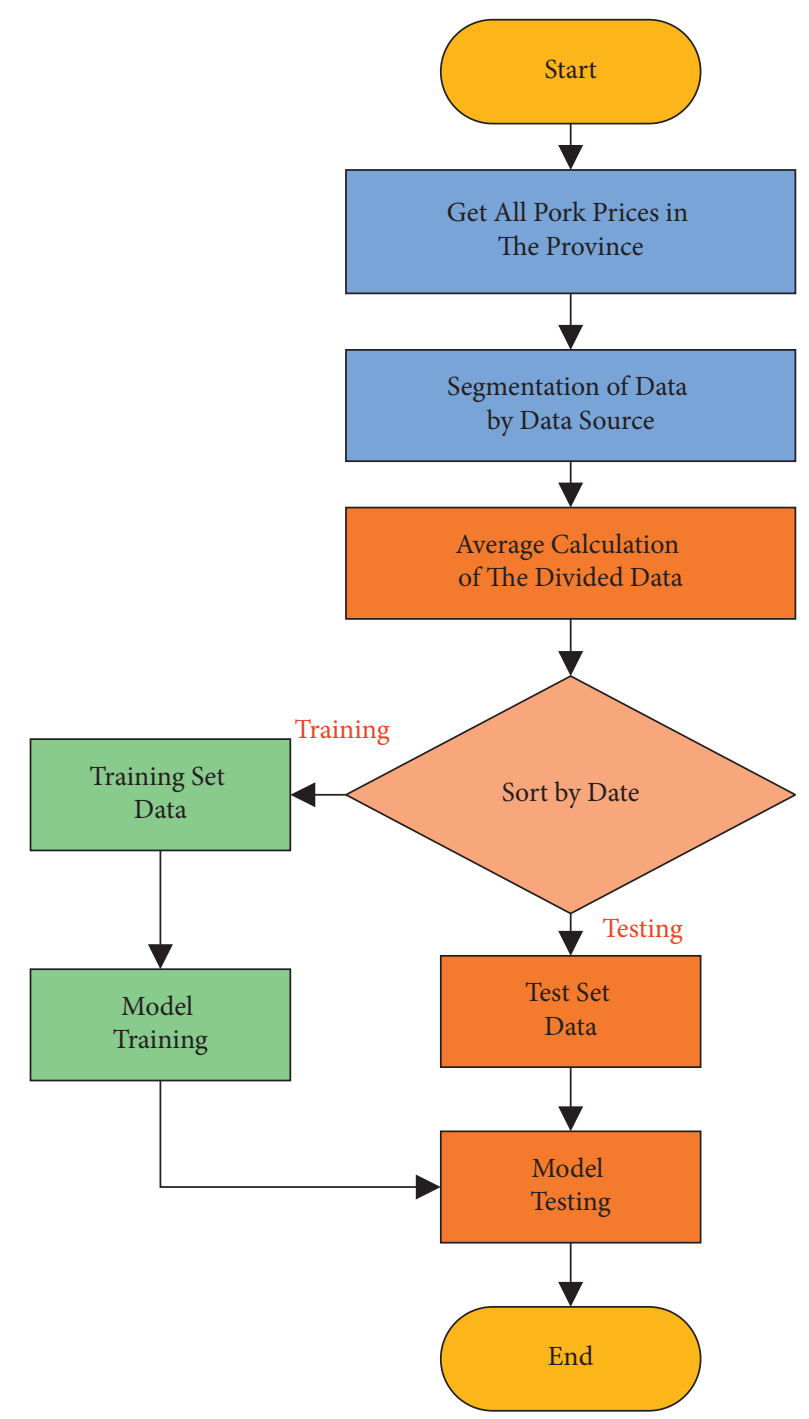

FIgURE 7: Calculation process of pork prices in different places.

(4) RMSE:

$$
\mathrm{RMSE}=\sqrt{\frac{1}{N} \sum_{t=1}^{N}\left(\hat{y}_{t}-y_{t}\right)^{2} .}
$$

In (15)-(18), $y_{t}$ represents the true value, $\hat{y} t$ stands for the predicted value, and $N$ refers to the total number of values.

\section{Model Test and Prediction Results of Pig Breeding}

3.1. Changes in Pig Breeding Costs. The cost of pig breeding is analyzed from two aspects of different scales and different structures combined with relevant pig breeding data, to give a better understanding of the change of the cost and benefit of pig breeding, Figure 8(a) shows the change trend of the cost of different scales of pig breeding. Figure 8(b) shows the change trend of structural cost of pig breeding industry.
Figure 8(a) reveals that with the increase of pig breeding scale, the cost of pig breeding gradually decreases. From 2005 to 2011, the cost of small-scale pig breeding is less than the total cost of total scale breeding; from 2009 to 2019, the total cost of small-scale pig breeding is greater than that of medium-scale pig breeding; from 2005 to 2007, the cost of smallscale pig breeding is less than that of large-scale pig breeding; from 2009 to 2019, the total cost of small-scale breeding is higher than that of large-scale breeding. Therefore, there are advantages in the feeding cost of small-scale pig breeding from 2005 to 2010, but with the increase of feed and land prices, the cost advantage of small-scale pig breeding disappears. Therefore, in this process, the advantages of largescale and intensive pig breeding have been gradually reflected. Figure 8(b) illustrates that the various costs and expenses of pig breeding industry are increasing, which also leads to the increase of feeding costs borne by small-scale pig breeders, the decrease of their income, and the acceleration of small-scale breeders withdrawing from the market. The cost of piglets shows volatile changes, which may be due to the fluctuation of 


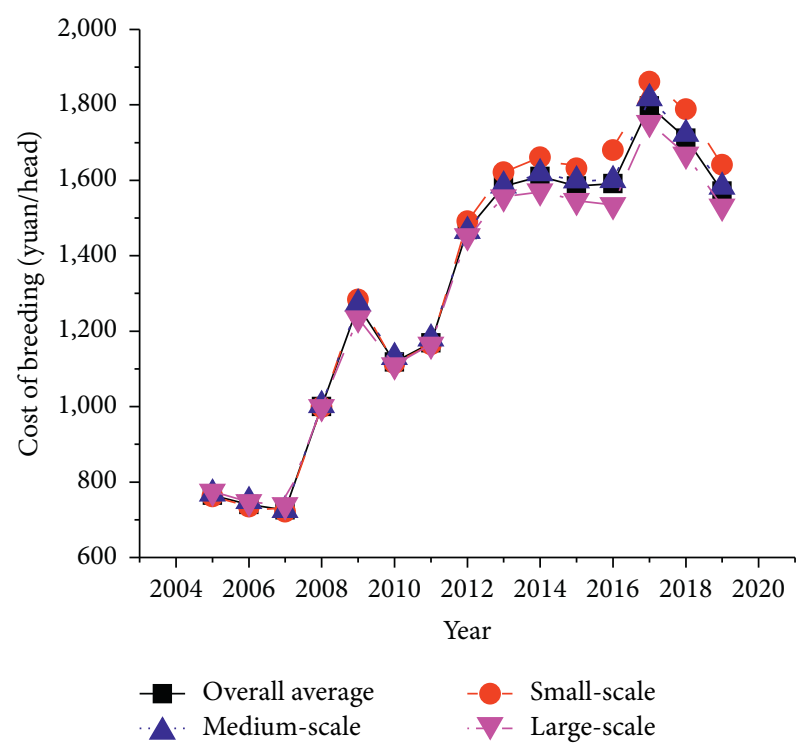

(a)

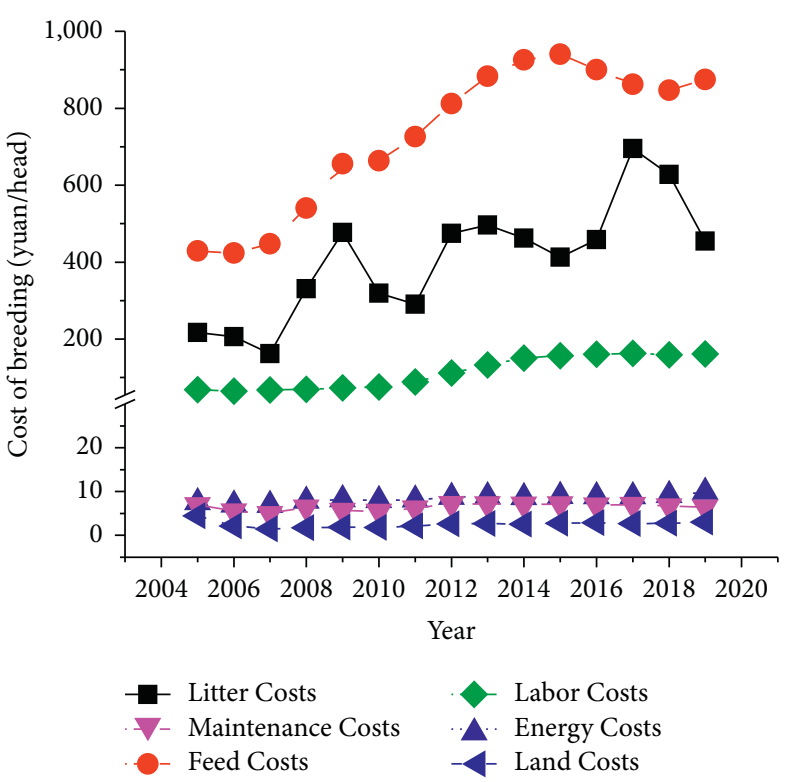

(b)

Figure 8: Cost of pig breeding industry: (a) different scale cost of pig breeding industry; (b) structural cost of pig breeding industry.

the number of piglets caused by the impact of pig breeding prices in the previous year, which in turn affects the cost of piglets in the next year. Figure 8(a) demonstrates that the price of pigs also fluctuated in 2008, which may be due to the influence of the price of piglets in 2008, and the change of the price of pigs in the next few years is similar to the fluctuation form of the price of piglets. Due to the influence of other factors, the total breeding cost shows an upward trend.

3.2. Model Prediction Results. The prices of live pigs during a total of 31 days in August of 2018 in Shaanxi Province are randomly chosen to test the predicting accuracy of the model designed here. The orange line in Figure 9 indicates the actual price curve of the market price of live pigs. Comparison is made between the results of BP neural network (BPNN), support vector regression algorithm (SVR), and convolutional neural networks (CNN), and Figure 9 displays the results.

Figure 9 shows that the real price of pigs in August has experienced rising, falling, and rising again. However, generally speaking, the pork price shows an upward trend. Compared with the experimental results of several prediction algorithms, the overall trend of BP neural network is relatively stable. Results of SVR algorithm and CNN show an upward trend of pork price, while the results of the LSTM algorithm are relatively stable. The reason may be that LSTM algorithm can retain the correlation information in the historical data of pig price, while other algorithms can only retain the short-term information in the iterative process, which affects the prediction results of the model. The model based on LSTM neural network can predict the pork price well.

To verify the effectiveness of the designed algorithm, LSTM algorithm, CNN algorithm, and BP algorithm are

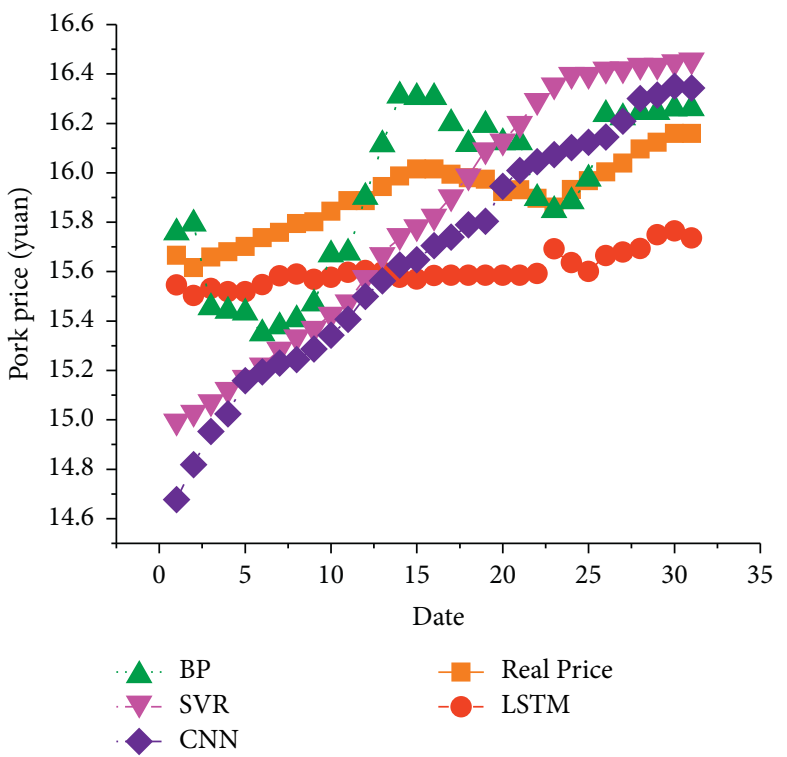

Figure 9: Model simulation results.

tested with three different pig price data sets: state price, market price, and website price. Figure 10 shows the results.

Figure 10 reveals that the prediction accuracy of the designed LSTM algorithm on different data sets is over $80.1 \%$, higher than that of BP algorithm and CNN algorithm. Therefore, after processing based on the LSTM model, the algorithm can effectively predict the change of the future hog price.

3.3. Performance of Model Prediction under Environmental Regulation. In Section 2.3, study is made on the total factor productivity of pig breeding under environmental 


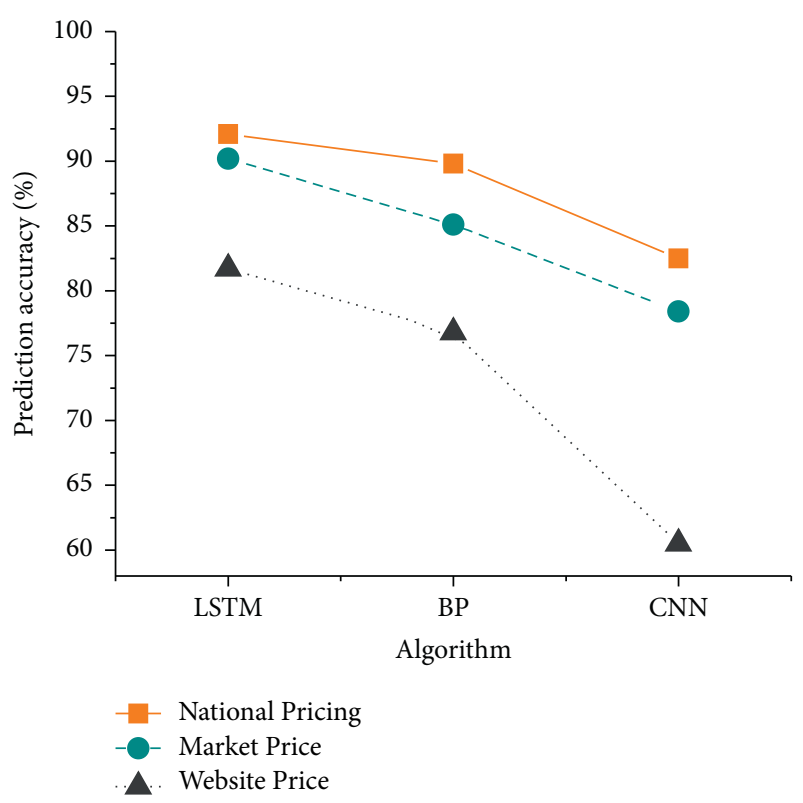

Figure 10: Comparison of face recognition results.

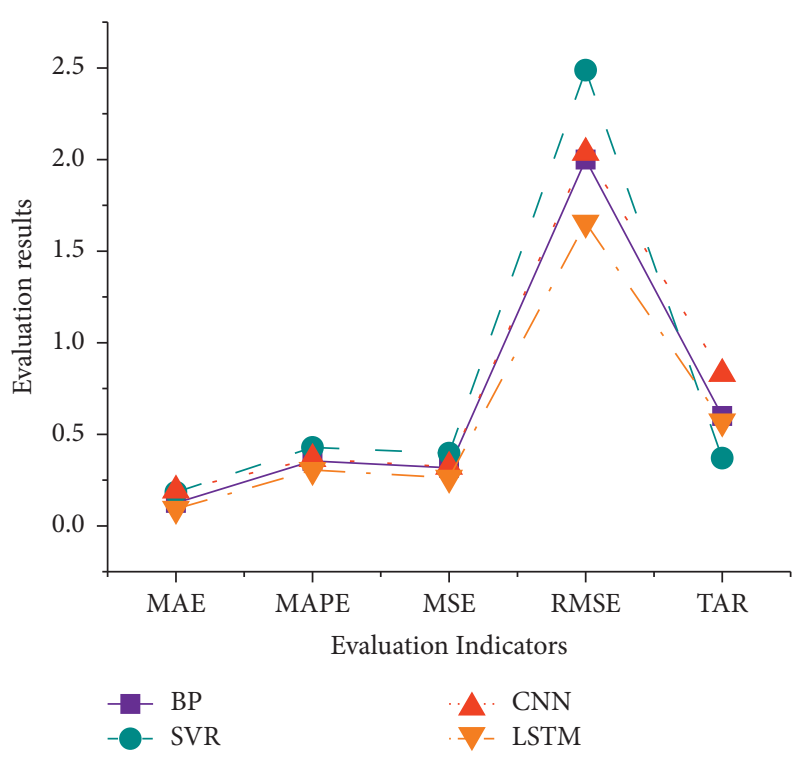

FIGURE 11: Comparative analysis of model performance.

regulation. Combined with the existing research results, analysis is made on the prediction effect of the model under environmental regulation. In addition, comparison is made between the experimental results of BPNN, SVR, and CNN algorithms. Figure 11 displays the experimental results.

Figure 11 reveals that the prediction performance of LSTM model is the best in four of the five indexes and that the average absolute error is around 0.1. Comparing the difference between the predicted price and the real price, we find that the absolute error of BPNN model is the maximum. Compared with LSTM neural network, other models have larger deviation in prediction results. Moreover, the LSTM model has a prediction accuracy of 0.83 for the price trend of live pigs, which has the final stable trend prediction result.

\section{Conclusion}

This study is focussed on the production efficiency of pig breeding industry under environmental regulation. What is predicted with LSTM neural network is the pig price. The research process, firstly, analyzes the development of pig breeding industry and the environmental pollution caused by it and, then, introduces green total factor productivity to analyze the profit of pig breeding and the cost of environmental pollution under environmental regulation. The experimental results show that with the increase of breeding cost, small-scale pig breeding is gradually eliminated, and intensive and large-scale pig breeding is the development trend in the future, which makes the control of environmental pollution caused by pig breeding harder. The designed model can accurately predict the price of pigs; namely, the designed model can well solve the problem of pig breeding production efficiency under environmental regulation.

However, there are still some deficiencies. There are many aspects of the impacts of environmental regulation on pig breeding. Only the influencing factors of environmental pollution control were considered, while the change of pig price is also affected by many influencing factors. The study is only carried out on several important influencing factors. Therefore, various influencing factors will be comprehensively considered in follow-up research to better solve these deficiencies and use better algorithm to predict factors such as pork cost and profit.

\section{Data Availability}

The labeled data set used to support the findings of this study are available from the corresponding author upon request.

\section{Conflicts of Interest}

The authors declare no conflicts of interest.

\section{Acknowledgments}

This work was supported in part by the Key Consulting and Research Project of Chinese Academy of Engineering in 2020 (No. 2020-XZ-19), the Consulting and Research Project of Henan Academy of Engineering in 2021 (No. 2021HENZDA04), the General Project of Educational Science of Henan Province (No. 2021YB0050). Henan Science and Technology Think Tank Project (No. HNKJZK-2022-21B), and 2021 Strategic Research Project of the Education and Science Commission of the Ministry of Education (No. 29).

\section{References}

[1] Y. Xue, W. Luan, H. Wang, and Y. J. Yang, "Environmental and economic benefits of carbon emission reduction in animal husbandry via the circular economy: case study of pig farming in Liaoning, China," Journal of Cleaner Production, vol. 238, Article ID 117968, 2019.

[2] Y. Lam, J. P. Fry, and K. E. Nachman, "Applying an environmental public health lens to the industrialization of food 
animal production in ten low-and middle-income countries," Globalization and Health, vol. 15, no. 1, pp. 1-20, 2019.

[3] R. Espinosa, D. Tago, and N. Treich, "Infectious diseases and meat production," Environmental and Resource Economics, vol. 76, no. 4, pp. 1019-1044, 2020.

[4] K. Ye, Y. Piao, K. Zhao, and X. Cui, "A heterogeneous graph enhanced LSTM network for hog price prediction using online discussion," Agriculture, vol. 11, no. 4, p. 359, 2021.

[5] J. Biddle, "Statistical inference in economics in the 1920s and 1930sThe crop and livestock forecasts of the US department of agriculture," History of Political Economy, vol. 26, pp. 53-80, 2021.

[6] S. Xie, Z. Yu, and Z. Lv, "Multi-disease prediction based on deep learning: a survey," CMES-Computer Modeling in Engineering and Sciences, vol. 127, no. 3, pp. 1-34, 2021.

[7] D. Pan, J. Tang, L. Zhang, M. He, and C.-C. Kung, "The impact of farm scale and technology characteristics on the adoption of sustainable manure management technologies: evidence from hog production in China," Journal of Cleaner Production, vol. 280, Article ID 124340, 2021.

[8] D. Xie, L. Zhuo, P. Xie, Y. Liu, B. Feng, and P. Wu, "Spatiotemporal variations and developments of water footprints of pig feeding and pork production in China (2004-2013)," Agriculture, Ecosystems \& Environment, vol. 297, Article ID 106932, 2020.

[9] Y. Woonwong, D. Do Tien, and R. Thanawongnuwech, "The future of the pig industry after the introduction of African swine fever into Asia," Animal Frontiers, vol. 10, no. 4, pp. 30-37, 2020.

[10] M. Costantini, J. Bacenetti, G. Coppola, L. Orsi, A. Ganzaroli, and M. Guarino, "Improvement of human health and environmental costs in the European Union by air scrubbers in intensive pig farming," Journal of Cleaner Production, vol. 275, Article ID 124007, 2020.

[11] Z. Ni, J. I. Chen, and J. Ding, "Pig farmers' willingness to recover their production under COVID-19 pandemic shock in China-Empirical evidence from a farm survey," Journal of Integrative Agriculture, vol. 19, no. 12, pp. 2891-2902, 2020.

[12] Y. Yang, S. Xing, Y. Chen et al., "Profiles of bacteria/phagecomediated ARGs in pig farm wastewater treatment plants in China: association with mobile genetic elements, bacterial communities and environmental factors," Journal of Hazardous Materials, vol. 404, Article ID 124149, 2021.

[13] C. Secco, L. M. D. Luz, E. Pinheiro et al., "Circular economy in the pig farming chain: proposing a model for measurement," Journal of Cleaner Production, vol. 260, Article ID 121003, 2020.

[14] J. Johnston and L. Cushing, "Chemical exposures, health, and environmental justice in communities living on the fenceline of industry," Current environmental health reports, vol. 7 , no. 1, pp. 48-57, 2020.

[15] Y. Takahashi, H. Nomura, and C. T. Son, "Manure management and pollution levels of contract and non-contract livestock farming in Vietnam," The Science of the Total Environment, vol. 710, Article ID 136200, 2020.

[16] B. Yan, J. Yan, W. Shi, and Y. Li, "Study on the comprehensive comparative advantages of pig production and development in China based on geographic information system," Clean Technologies and Environmental Policy, vol. 22, no. 1, pp. 105-117, 2020.

[17] E. Nie, G. Zheng, and C. Ma, "Characterization of odorous pollution and health risk assessment of volatile organic compound emissions in swine facilities," Atmospheric Environment, vol. 223, Article ID 117233, 2020.
[18] K. W. R. Chan and G. Enticott, "The Suzhi farmer:Constructing and contesting farming Subjectivities in post-Socialist China," Journal of Rural Studies, vol. 67, pp. 69-78, 2019.

[19] Z. I. Kimera, G. Frumence, L. E. G. Mboera, M. Rweyemamu, S. E. Mshana, and M. I. N. Matee, "Assessment of drivers of antimicrobial use and resistance in poultry and domestic pig farming in the msimbazi river basin in Tanzania," Antibiotics, vol. 9, no. 12, p. 838, 2020.

[20] A. H. Bukhari, M. A. Z. Raja, M. Sulaiman, S. Islam, M. Shoaib, and P. Kumam, "Fractional neuro-sequential ARFIMA-LSTM for financial market forecasting," IEEE Access, vol. 8, Article ID 71326, 2020.

[21] T. Kuhn, D. Schäfer, K. Holm-Müller, and W. Britz, "On-farm compliance costs with the EU-Nitrates Directive: a modelling approach for specialized livestock production in northwest Germany," Agricultural Systems, vol. 173, pp. 233-243, 2019.

[22] Q. Liang and X. Wang, "Cooperatives as competitive yardstick in the hog industry? - evid?:ence from China," Agribusiness, vol. 36, no. 1, pp. 127-145, 2020.

[23] E. Hsu, "Cost-benefit analysis for recycling of agricultural wastes in Taiwan," Waste Management, vol. 120, pp. 424-432, 2021.

[24] Y. Wang, J. Zhang, Y. Li et al., "Methane production from the co-digestion of pig manure and corn stover with the addition of cucumber residue: role of the total solids content and feedstock-to-inoculum ratio," Bioresource Technology, vol. 306, Article ID 123172, 2020.

[25] C. Zhou, Z. Fang, X. Xu et al., "Using long short-term memory networks to predict energy consumption of air-conditioning systems," Sustainable Cities and Society, vol. 55, Article ID 102000, 2020.

[26] M. Wang, "Short-term forecast of pig price index on an agricultural internet platform," Agribusiness, vol. 35, no. 3, pp. 492-497, 2019.

[27] F. Zhang and F. Wang, "Prediction of pork supply via the calculation of pig population based on population prediction model," International Journal of Agricultural and Biological Engineering, vol. 13, no. 2, pp. 208-217, 2020.

[28] V. Gundu and S. P. Simon, "PSO-LSTM for short term forecast of heterogeneous time series electricity price signals," Journal of Ambient Intelligence and Humanized Computing, vol. 12, no. 2, pp. 2375-2385, 2021.

[29] J. Klomp, "The impact of Russian sanctions on the return of agricultural commodity futures in the EU," Research in International Business and Finance, vol. 51, Article ID 101073, 2020.

[30] H. Jahangir, H. Tayarani, and S. S. Gougheri, "Deep learningbased forecasting approach in smart grids with microclustering and bidirectional LSTM network," IEEE Transactions on Industrial Electronics, vol. 68, no. 9, pp. 8298-8309, 2020. 